\title{
Pioneer in Subjective Quality of Life Research: Edward F. Diener
}

\author{
Edward F. Diener
}

Received: 9 November 2013 / Accepted: 10 November 2013 /Published online: 27 November 2013 (C) Springer Science+Business Media Dordrecht and The International Society for Quality-of-Life Studies (ISQOLS) 2013

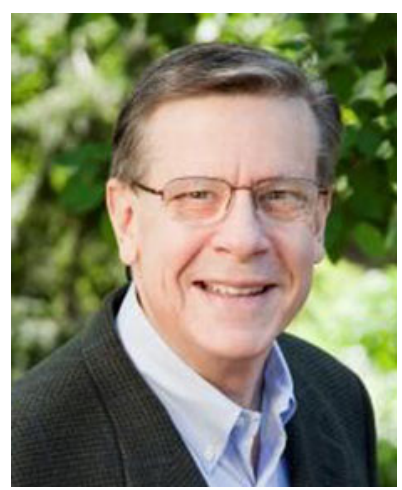

Edward "Ed" Diener was born in 1946 in Glendale, California, and grew up on a farm in the San Joaquin Valley of California. He received his bachelor's degree in 1968 at California State University at Fresno. He worked 2 years as an administrator for Kings View Community Mental Health Center. Diener attended the Ph.D. program in personality psychology at the University of Washington from 1970 to 1974, and conducted his dissertation research on deindividuation. His Halloween studies using trick-ortreaters as research participants are well-known. Diener had three major mentors during graduate school: Irwin Sarason, Ronald E. Smith, and Scott Fraser.

Ed Diener is married to forensic psychologist (both an attorney and clinical psychologist) Carol Diener, and three of their five children are psychologists. Marissa Diener is a developmental psychologist at the University of Utah and Mary Beth McGavran is a clinical psychologist at the University of Kentucky. Their son, Robert Biswas-Diener, is a psychologist who heads Positive Acorn, a consulting and coaching organization.

E. F. Diener $(\bowtie)$

University of Illinois, Champaign, IL, USA

e-mail: ediener@illinois.edu 
Ed Diener is the Joseph R. Smiley Distinguished Professor of Psychology, Emeritus, at the University of Illinois. He received his doctorate at the University of Washington in 1974, and has been a faculty member at the University of Illinois ever since. Dr. Diener was the president of both the International Society of Quality of Life Studies and the Society of Personality and Social Psychology. He was the first president of the International Positive Psychology Association. Diener was the editor of the Journal of Personality and Social Psychology, and one of the founding editors of the Journal of Happiness Studies. Diener was also the founding editor of Perspectives on Psychological Science. He has over 325 publications, with over 200 being in the area of the psychology of well-being.

Dr. Diener is a fellow of five professional societies, including the American Academy of Arts and Sciences. Professor Diener is listed as one of the most highly cited psychologists by the Institute of Scientific Information, and has over 75,000 citations to his credit. Diener has received the distinguished scientist award from the American Psychological Association, as well as the William James award for lifetime scientific contributions from the Association of Psychological Science. He also won the Distinguished Researcher Award from the International Society of Quality of Life Studies, the Gallup Academic Leadership Award, and the Jack Block Award for Personality Psychology. Dr. Diener has won several teaching awards, including the OakleyKundee Award for Undergraduate Teaching at the University of Illinois.

Professor Diener's research focuses on the measurement of well-being; temperament and personality influences on well-being; theories of well-being; income and wellbeing; and cultural influences on well-being. He finds in the first-ever representative sample of the world that there are some universal correlates of subjective well-being, such as interpersonal trust and respect, and also some culture-specific correlates. For example, self-esteem is more associated with life satisfaction in individualistic societies and less associated with it in collectivistic societies. Similarly, religion is a stronger correlate of life satisfaction in highly religious societies.

Diener has developed several scales that are in widespread use. For example, his Satisfaction with Life Scale has been cited over 8,000 times in the scientific literature, and his newer psychological flourishing scale is also being widely used. One of his current research interests is the outcomes of subjective well-being, such as health and longevity, citizenship, quality social relationships, and work productivity. He finds that in general "happiness" does not simply feel good, but helps the person function better. Another project Diener is working is working on is to have nations implement national accounts of well-being for use by policy makers and leaders.

Ed, Carol, and Robert Diener have created a website, Nobaproject.com (http:// nobaproject.com/), to publish free psychology information such as textbooks. An introductory text is on the site as of 2013, and more books are planned for the future.

Diener has edited three recent books on subjective well-being, and a 2005 book on multi-method measurement in psychology. Diener wrote a popular book on happiness with his son, Robert Biswas-Diener, and also authored a book on policy uses of accounts of well-being with Richard Lucas, Ulrich Schimmack, and John Helliwell. 